Jurnal PINUS: Jurnal Penelitian Inovasi Pembelajaran, 5 (2), 2020,11-16

Available online at: http://ojs.unpkediri.ac.id/index.

DOI: https://doi.org/10.29407/pn.v5i1.14283

\title{
Efektivitas Aplikasi Dokter sebagai Media Tutorial pada Materi Rekam Medis di STIKES Bhakti Husada Bengkulu
}

\author{
Agus Riyanto \\ agusriyanto105@gmail.com \\ STIKES Bhakti Husada Bengkulu
}

\begin{abstract}
Abstrak
Penelitian ini bertujuan untuk mengetahui tingkat efektivitas dari Aplikasi Dokter sebagai Media Tutorial pada Materi Rekam Medis yang telah dikembangkan. Jenis penelitian ini adalah penelitian pengembangan (Research and Development) dengan mengadopsi prosedur Analysis, Design, Development. Implementation, dan Evaluation (ADDIE). Penelitian dilakukan dalam tiga tahap yaitu: terdiri tahap analisis (analysis), tahap perancangan (design), dan tahap pengembangan (development). Pada tahap pengembangan dilakukan uji efektivitas. Uji efektivitas Animasi Dokter dilakukan pada mahasiswa Program Studi Keperawatan Semester I berjumlah 26 mahasiswa. Instrumen penelitian ini adalah lembar efektivitas animasi dokter. Hasil penelitian menunjukkan bahwa tingkat efektivitas animasi dokter model tutorial pada pokok bahasan rekam medis di semester I (satu) termasuk dalam kategori sangat dari aspek aktivitas mahasiswa dan dosen, respon mahasiswa dan tes hasil belajar mahasiswa dengan skor 4,24 .
\end{abstract}

Kata Kunci: Perangkat Lunak, Tutorial, Rekam Medis.

\begin{abstract}
This research aims to determine the effectiveness of the Interactive Multimedia Medical Record Material that has been developed. This type of research is a research and development $(R \& D)$ by adopting the procedure of Analysis, Design, Development. Implementation, and Evaluation (ADDIE). The research was conducted in three stages, namely: consisting of the analysis phase, the design phase, and the development stage. At the development stage an effectiveness test is performed. The effectiveness test of Doctor Animation was conducted on 26 semester I Nursing Study Program study. The instrument of this study was the doctor's effectiveness animation sheet. The results showed that the level of effectiveness of the animated animation model tutorial on the subject of medical records in the first semester (one) included in the category of very effective aspects of student and lecturer activities, student responses, and student learning outcomes tests with a score of 4.24.
\end{abstract}

Keywords: Software, Tutorial, Medical Record

\section{PENDAHULUAN}

Rekam medis merupakan berkas yang berisi catatan dan dokumen tentang identitas pasien, pemeriksaan, pengobatan, tindakan, dan pelayanan lain yang telah diberikan kepada pasien (Undang-Undang No. 29, 2004). Isi 
Jurnal PINUS: Jurnal Penelitian Inovasi Pembelajaran, 5 (2), 2020, Agus Riyanto

rekam medis merupakan uraian identitas pasien, pemeriksaan pasien, diagnosis, pengobatan, tindakan, dan pelayanan lain baik dilakukan oleh dokter dan dokter gigi maupun tenaga kesehatan lainnya sesuai kompetensinya dan dokumen yang merupakan kelengkapan dari catatan tersebut, antara lain foto rontgen, hasil laboratorium dan keterangan lain sesuai dengan kompetensi keilmuannya (Konsil Kedokteran Indonesia, 2006). Selama proses pembelajaran Sistem Informasi Kesehatan, dosen lebih aktif menjelaskan materi menggunakan media pembelajaran Microsoft Powerpoint dan mahasiswa dituntut mendengar, mencatat penjelasan dosen, serta menyelesaikan latihan soal-soal yang ditentukan oleh dosen. Hal ini yang membuat pembelajaran Sistem Informasi Kesehatan yang masih bersifat teacher centered yaitu pembelajaran yang masih berpusat pada dosen. Salah satu cara yang membuat proses pembelajaran lebih menyenangkan, dan lebih bersifat interaktif adalah dengan menggunakan media pembelajaran yang lebih interaktif. Pemilihan media pembelajaran yang tepat untuk mahasiswa akan memudahkan dan menumbuhkan minat belajar pada materi tertentu.

\begin{tabular}{|c|c|}
\hline Aplikasi & Dokter \\
\hline dikembangkan & diharapkan \\
\hline enumbuhkan & pengalaman \\
\hline ahasisw & $\mathrm{m \epsilon}$ \\
\hline menjalankan & proses \\
\hline elektronik. & Pemanfaatan \\
\hline ses & i \\
\hline
\end{tabular}

pembelajaran yang membosankan menjadi pembelajaran yang menyenangkan. Ketertarikan mahasiswa akan media pembelajaran, juga akan meningkatkan motivasi belajar mahasiswa. Memungkinkan mahasiswa melakukan eksplorasi data dan informasi secara lebih luas dan praktis. Pemanfaatan komputer dalam berbagai bidang pekerjaan dapat meningkatkan kinerja dan memungkinkan kegiatan dapat dilakukan dengan cepat, tepat, dan akurat. Pemanfaatan komputer juga merupakan instrumen bagi dosen untuk pengembangan media pembelajaran aplikasi dokter. Dengan berkembangnya media pembelajaran berbantuan teknologi komputer dapat memudahkan peserta didik untuk mendapat sumber belajar yang lebih luas dan praktis sehingga tidak hanya memanfaatkan atau menggunakan buku cetak saja.

Hasil observasi dilakukan selama perkuliahan berjalan ditemukan hambatan dalam proses belajar mengajar, yaitu kurangnya pemahaman mahasiswa dalam materi rekam medis selama ini, kemudian kurang maksimalnya pemanfaatan media pembelajaran dengan unsur perangkat lunak yang mendukung.

Penelitian ini dilakukan dalam rangka mengefektifkan sebuah media pembelajaran dengan menggunakan aplikasi dokter. Efektivitas media pembelajaran dilakukan pada materi rekam medis berbasis elektronik agar dapat disampaikan menggunakan software menarik, sehingga pembelajaran tidak membosankan. 
Jurnal PINUS: Jurnal Penelitian Inovasi Pembelajaran, 5 (2), 2020, Agus Riyanto

Berdasarkan latar belakang yang

telah dikemukakan di atas, maka rumusan masalah yang akan dikaji dalam penelitian ini adalah Bagaimana tingkat efektivitas dari media pembelajaran aplikasi dokter digunakan sebagai model tutorial materi rekam medis yang telah dikembangkan? Adapun tujuan penelitian ini adalah untuk mengetahui tingkat efektivitas dari media pembelajaran aplikasi dokter sebagai model tutorial materi rekam medis elektronik yang telah dikembangkan.

\section{A. Model Pembelajaran Interaktif}

Model pembelajaran multimedia interaktif adalah proses pembelajaran dimana penyampaian materi, diskusi, dan kegiatan pembelajran lain dilakukan melalui media komputer (Darmadi, 2017; Zaid \& Mohamad, 2010; Longmire, Tuso, \& Wagner, 2000). (Huda, 2013) menekankan pentingnya media sebagai alat untuk merangsang proses belajar. Sistem pembelajaran lebih inovatif dan interaktif, pengajar akan selalu dituntut untuk kreatif, inovatif dalam mencari terobosan pembelajran, mampu menggabungkan antara teks, gambar, audio, musik, animasi gambar, atau video dalam satu kesatuan yang saling mendukung guna tercapainya tujuan pembelajaran (Saputra \& Purnama, 2011).

\section{B. Model Tutorial}

Tutorial didefinisikan sebagai bentuk pembelajaran khusus dengan pembimbing yang terkualifikasi, penggunaan komputer untuk tutorial pembelajaran. Tutorial dengan metode alternatif diantaranya bacaan, demonstrasi, penemuan bacaan, atau pengalaman yang membutuhkan respon secara verbal dan tulisan serta adanya tujuan.

Tutorial adalah bimbingan pembelajaran dalam bentuk pemberian arahan, bantuan, petunjuk, dan motivasi agar para siswa belajar secara efisien dan efektif. Pemberian bantuan berarti membantu siswa dalam mempelajari materi pembelajaran. Petunjuk berarti memberikan informasi tentang cara belajar secara efisien dan efektif. Arahan berarti mengarahkan para mahasiswa untuk mencapai tujuan masing-masing. Motivasi berarti menggerakkan kegiatan parasiswa dalam mempelajari materi, mengerjakan tugas-tugas dan mengikuti penilaian. Bimbingan berarti membantu para mahasiswa memecahkan masalahmasalah belajar.

\section{Software Aplikasi}

Menurut (Hasyim \& Listiawan, 2015), Software (Perangkat Lunak) adalah rangkaian instruksi elektronik yang memerintahkan komputer untuk melakukan tugas tertentu sesuai dengan perintah yang diberikan oleh seorang pengguna komputer. Animasi adalah urutan frame yang ketika diputar dalam frame dengan kecepatan yang cukup dapat menyajikan gambar bergerak lancer seperti sebuah film atau video. Animasi juga dapat diartikan dengan menghidupkan gambar, sehingga anda perlu mengetahui dengan pasti setiap detail karakter anda, mulai dari tampak (depan, belakang, 3/4, dan samping) detail muka si karakter dalam berbagai ekspresi (normal, diam, marah, senyum, ketawa, kesal, dan lainnya) lalu pose/gaya khas karakter bila sedang 
Jurnal PINUS: Jurnal Penelitian Inovasi Pembelajaran, 5 (2), 2020, Agus Riyanto

melakukan kegiatan tertentu yang menjadi ciri khas si karakter tersebut. (Saputra \& Purnama, 2011).

Sofware animasi adalah Perangkat Lunak yang memuat efek-efek untuk menyajikan gambar bergerak lancar, sehingga gambar tersebut menjadi lebih hidup, menarik, dan interaktif. Pembuatan media pembelajaran pada penelitian ini menggunakan software macromediaflash 8 dengan animasi 2D. Animasi 2D adalah penciptaan gambar bergerak dalam lingkungan dua dimensi. Hal ini dilakukan dengan urutan gambar berturut-turut atau "frame" yang mensimulasikan gerak oleh setiap gambar menunjukkan berikutnya dalam perkembangan bertahap langkahlangkah.

\section{METODE}

Jenis penelitian yang akan digunakan dalam penelitian ini adalah penelitian dan pengembangan (Research and development). Menurut Soenarto Intan Septiani, (2016) (dalam Tegeh, Jampel, \& Pudjawan, 2015: xii) penelitian pengembangan adalah upaya untuk mengembangkan dan menghasilkan suatu produk berupa materi, media, alat, dan/atau strategi pembelajaran, digunakan untuk mengatasi pembelajaran di kelas/laboratorium, dan bukan untuk menguji teori. Penelitian pengembangan ini menggunakan model ADDIE, model ADDIE merupakan salah satu model desain pembelajaran sistematik. ADDIE merupakan singkatan Analysis, Design, Developmentor

Production,
Implementation Delivery and Evaluation. Penelitian ini hanya dilakukan tiga tahap penelitian yakni tahap analisis, desain, dan pengembangan.

Sasaran dalam penelitian efektivitas media pembelajaran aplikasi dokter adalah mahasiswa semester I (satu) Program Studi Keperawatan. Subjek uji coba lapangan terdiri dari 26 mahasiswa semester I (satu) Program Studi Keperawatan. Instrumen yang digunakan dalam penelitian ini adalah lembar-lembar angket respon mahasiswa, lembar pengamatan aktivitas dosen dan mahasiswa, dan tes hasil belajar. Teknik pengumpulan data yang dilakukan dalam penelitian ini adalah pengumpulan keefektifan media pembelajaran. Teknik analisis data yang digunakan adalah analisis efektivitas.

\section{HASIL DAN PEMBAHASAN}

Hasil penelitian pengembangan ini diperoleh dari uji efektivitas media pembelajaran.

\section{Uji efektivitas}

Uji efektivitas dilakukan untuk melihat keefektifan media pembelajaran. Media pembelajaran ini diujicobakan pada 26 mahasiswa semester I (satu) Program Studi Keperawatan yang sedang mengikuti pembelajaran Sistem Informasi Kesehatan submateri Rekam Medis. Uji efektivitas dilakukan di STIKES Bhakti Husada Bengkulu. Hasil uji efektivitas memberikan data berupa aktivitas dalam kegiatan belajar mengajar yang terdiri dari aktivitas mahasiswa dan aktivitas dosen/pengajar 
Jurnal PINUS: Jurnal Penelitian Inovasi Pembelajaran, 5 (2), 2020, Agus Riyanto

dalam proses pembelajaran, respon belajar. Berikut hasil uji fektifitas dapat mahasiswa terhadap media dan tes hasil dilihat pada Tabel.

Tabel Hasil ujie fektifitas

\begin{tabular}{lll}
\hline Analisis & Rata-Rata & Kriteria \\
\hline Aktivitas Mahasiswa & $\mathbf{4 , 1 0}$ & Efektif \\
\hline Aktivitas Dosen & $\mathbf{4 , 3 7}$ & Sangat efektif \\
\hline Respon Mahasiswa & $\mathbf{4 , 1 6}$ & Efektif \\
\hline Tes Hasil Belajar & $\mathbf{4 , 3 3}$ & Sangat efektif \\
\hline $\begin{array}{l}\text { Skor rata-rata } \\
\text { Uji efektivitas }\end{array}$ & $\mathbf{4 , 2 4}$ & Sangat efektif \\
\hline
\end{tabular}

Berdasarkan analisis data terlihat bahwa tingkat efektivitas produk media pembelajaran termasuk dalam kategori sangat efektif. Hal ini menunjukkan bahwa media layak digunakan dan memberikan manfaat pada proses pembelajaran. Hal ini juga diperkuat oleh respon mahasiswa yang menyatakan media pembelajaran efektif digunakan serta hasil belajar. Ini dilihat dari besarnya presentase jumlah mahasiswa yang lulus mata kuliah sebesar 80,6\% sehingga dapat dikatakan bahwa secara keseluruhan mahasiswa telah mencapai kompetensi yang telah ditentukan.

Berdasarkan analisis tersebut, maka media dapat digunakan dengan melakukan beberapa perbaikan atau revisi menyesuaikan saran dan masukan dari mahasiswa maupun dosen hingga menghasilkan media pembelajaran yang final.

\section{KESIMPULAN}

Berdasarkan hasil penelitian media pembelajaran aplikasi dokter sebagai model tutorial pada pokok bahasan rekam medis di mahasiswa semester I (satu) Program Studi Keperawatan diperoleh kesimpulan tingkat efektivitas media pembelajaran aplikasi dokter pada pokok bahasan rekam medis di mahasiswa semester I (satu) Program Studi Keperawatan termasuk dalam kategori sangat efektif dengan skor 4,24.

\section{SARAN}

Saran-saran yang dapat diberikan penulis adalah sebagai berikut:

1. Media pembelajaran ini perlu dibuat lebih variatif lagi dan lebih banyak mencakup proses pelayanan pasien.

2. Media pembelajaran aplikasi dokter hendaknya dilengkapi dengan fasilitas audio untuk menunjang belajar mengajar.

\section{DAFTAR RUJUKAN}

Darmadi. (2017). Pengembangan Model dan Metode Pembelajaran dalam Dinamika Belajar Siswa. In 
Jurnal PINUS: Jurnal Penelitian Inovasi Pembelajaran, 5 (2), 2020, Agus Riyanto

Deepublish.

Hasyim, M., \& Listiawan, T. (2015).

Penerapan Aplikasi Ibm Spss Untuk

Analisis Data Bagi Pengajar

Pondok Hidayatul Mubtadi' in

Ngunut Tulungagung Demi

Meningkatkan Kualitas

Pembelajaran dan Kreativitas Karya

Ilmiah Guru. Jurnal Pengabdian

Kepada Masyarakat.

Huda, M. (2013). Model-model pengajaran dan pembelajaran. Teaching and Educations.

konsil kedokteran indonesia. (2006).

Konsil Kedokteran Indonesia

(KKI). Konsil Kedokteran

Indonesia $(K K I)$.

Longmire, W., Tuso, G., \& Wagner, E.

D. (2000). Emerging strategies for effective e-Learning solutions. Learning Without ....

Presiden Republik Indonesia. (2004).

Undang Undang Republik

Indonesia Nomor 29 Tahun 2004

Tentang Praktik Kedoteran.

Undang Undang Praktik

Kedokteran.

https://doi.org/10.1017/CBO978110
7415324.004

Saputra, W., \& Purnama, B. E. (2011). Pengembangan multimedia pembelajaran interaktif untuk mata kuliah organisasi komputer. SpeedSentra Penelitian Engineering Dan Edukasi, 4(2).

Soenarto Intan Septiani, Y. . R. (2016). Pengaruh Penerapan Model Pembelajaran Auditory, Intellectually, Repetition (AIR) Melalui Metode Think Pair Share (TPS) Terhadap Hasil Belajar Fisika Siswa. Omega: Jurnal Fisika Dan Pendidikan Fisika.

Tegeh, I. M., Jampel, I. N., \& Pudjawan, K. (2015). Pengembangan Buku Ajar Model Penelitian Pengembangan dengan Model ADDIE. Seminar Nasional Riset Inovatif IV.

Zaid, N. M., \& Mohamad, F. (2010). Pembangunan Modul Multimedia Interaktif Menggunakan Pendekatan Pembelajaran Berasaskan Senario Bagi Tajuk Pembangunan Perisian Multimedia Berasaskan. ... Tajuk Pembangunan Perisian Multimedia .... 